\title{
Stroma modifies relationships between risk factor exposure and age-related epithelial involution in benign breast
}

\author{
Lynn Chollet-Hinton $\mathbb{1}^{1} \cdot$ Samantha Puvanesarajah ${ }^{1} \cdot$ Rupninder Sandhu ${ }^{2}$. Erin L. Kirk ${ }^{1}$ Bentley R. Midkiff $\mathbb{C}^{2}$ • \\ Karthik Ghosh ${ }^{3} \cdot$ Kathleen R. Brandt ${ }^{4}$. Christopher G. Scott $\mathbb{B}^{5} \cdot$ Gretchen L. Gierach $^{6} \cdot$ Mark E. Sherman $^{6}$. \\ Celine M. Vachon ${ }^{7} \cdot$ Melissa A. Troester ${ }^{1,2,8}$
}

Received: 20 June 2017 / Revised: 3 January 2018 / Accepted: 3 January 2018 / Published online: 20 February 2018

(c) United States \& Canadian Academy of Pathology 2018

\begin{abstract}
Delayed age-related lobular involution has been previously associated with elevated breast cancer risk. However, intraindividual variability in epithelial involution status within a woman is undefined. We developed a novel measure of agerelated epithelial involution, density of epithelial nuclei in epithelial areas using digital image analysis in combination with stromal characteristics (percentage of section area comprising stroma). Approximately 1800 hematoxylin and eosin stained sections of benign breast tissue were evaluated from 416 participants having breast surgery for cancer or benign conditions. Two to sixteen slides per woman from different regions of the breast were studied. Epithelial involution status varied within a woman and as a function of stromal area. Percentage stromal area varied between samples from the same woman (median difference between highest and lowest stromal area within a woman was 7.5\%, but ranged from 0.01 to $86.7 \%$ ). Restricting to women with at least $10 \%$ stromal area $(N=317)$, epithelial nuclear density decreased with age $\left(-637.1 \mathrm{cells} / \mathrm{mm}^{2} \mathrm{per}\right.$ decade of life after age 40, $p<0.0001)$, increased with mammographic density $\left(457.8\right.$ cells $/ \mathrm{mm}^{2}$ per increasing BI-RADs density category $p=0.002)$, and increased non-significantly with recent parity, later age at first pregnancy, and longer and more recent oral contraceptive use. These associations were attenuated in women with mostly fat samples $(<10 \%$ stroma $(N$ $=99)$ ). Thirty-one percent of women evaluated had both adequate stroma $(\geq 10 \%)$ and mostly fat $(<10 \%$ stroma) regions of breast tissue, with the probability of having both types increasing with the number breast tissue samplings. Several breast cancer risk factors are associated with elevated age-related epithelial content, but associations depend upon stromal context. Stromal characteristics appear to modify relationships between risk factor exposures and breast epithelial involution.
\end{abstract}

Melissa A. Troester

troester@unc.edu

1 Department of Epidemiology, University of North Carolina at Chapel Hill, Chapel Hill, NC, USA

2 Lineberger Comprehensive Cancer Center, University of North Carolina at Chapel Hill, Chapel Hill, NC, USA

3 Department of Internal Medicine, Mayo Clinic College of Medicine, Rochester, MN, USA

4 Department of Radiology, Mayo Clinic College of Medicine, Rochester, MN, USA

5 Division of Biostatistics, Department of Health Sciences Mayo Clinic College of Medicine Rochester, MN, USA

6 Division of Cancer Epidemiology and Genetics, National Cancer Institute, Bethesda, MD, USA

7 Division of Epidemiology, Department of Health Sciences Mayo Clinic College of Medicine Rochester, MN, USA

8 Department of Pathology and Laboratory Medicine, University of North Carolina at Chapel Hill, Chapel Hill, NC, USA

\section{Introduction}

The majority of benign breast epithelial cells among young women are present in structures termed terminal duct lobular units, which lose epithelial content and complexity with advancing age and menopause (i.e. involution). Several studies have demonstrated that histology of benign breast epithelium is associated with breast cancer risk, with more complete epithelial involution conferring reduced risk of breast cancer [1-4]. It has been hypothesized that some well-established breast cancer risk factors (most notably mammographic density, parity, and menopause) are associated with age-related involution of epithelium, with consequences for etiology or risk [2, 5-10]. Thus, identifying the best method for quantifying involution has potential etiologic, and translational importance.

However, research on benign histology as a biomarker of breast cancer risk has been constrained by availability of 
biospecimens $[9,11]$ and uncertainty as to whether a single breast biospecimen represents a woman's involution status. Several studies have evaluated multiple specimens from a single patient and reported high within-person agreement for measures of breast involution [1, 5, 6, 12], while others have identified variability within an individual $[13,14]$. Research is needed to systematically evaluate intraindividual variability in epithelial involution status. We propose that epithelial composition may be heterogeneous throughout the breast, with higher levels in non-fatty, mammographically dense tissue, which is the background in which most breast cancers develop [15].

In the current analysis, we used a digital histology approach to measure stroma and epithelial characteristics in the same specimens. We measured percent area of stroma and epithelium, as well as epithelial nuclear density as a measure of epithelial involution status [16]. Our goals were to understand intraindividual variability, to assess the relationship between stromal content and epithelial involution measures, and to assess risk factor-histology associations after considering multiple samples. Over 400 women are included in the current analysis, which applied novel digital imaging algorithms to quantify epithelial and stromal histological features on approximately 1800 distinct hematoxylin and eosin (H\&E)-stained slides. Some findings were independently validated in a separate data set from the Mayo Clinic, with local mammographic imaging data.

\section{Materials and methods}

\section{Study population}

The Normal Breast Study is a study of breast cancer microenvironment and normal breast tissue conducted at the University of North Carolina (UNC) Hospitals in Chapel Hill, NC. As described previously [16], English-speaking women $\geq 18$ years of age undergoing breast surgery at UNC Hospitals (mastectomy, lumpectomy, excisional biopsy, reduction mammoplasty, or other cosmetic breast surgery) between October 2009 and April 2013 were contacted for participation by study personnel during a pre-surgery appointment with their surgeon. The final Normal Breast Study population included 399 women with breast cancer and 75 women with benign breast histology, for a total of 474 participants. Written informed consent was obtained for all enrolled participants, and all study protocols were approved by the UNC School of Medicine's Institutional Review Board.

Participants completed a telephone interview to provide demographic, lifestyle, and risk factor exposure data, and medical records abstraction was performed to obtain patients' medical history, mammographic screening, surgical details, and tumor pathology data. Age and body mass index $\left(<25.0,25.0-29.9, \geq 30.0 \mathrm{~kg} / \mathrm{m}^{2}\right)$ were defined at time of surgery using medical records. Mammographic density was abstracted from medical records and defined from mammograms taken at time of breast cancer diagnosis (breast cancer patients) or the most recent mammogram prior to surgery (patients with benign breast histology) using standard Breast Imaging Reporting and Data System (BI-RADS) scores, 4th edition (1-Fatty, 2-Scattered fibroglandular densities, 3-Heterogeneously dense, and 4 -Extremely dense) [17] assigned by a radiologist. For a small subset of patients $(N=33)$, mammographic density was defined as "dense, not otherwise specified", as the radiologist reported breast density as "dense" without distinction between BI-RADS category 3 or 4 . Pathologic data (including diagnosis status, sampled breast quadrant, and surgery type) were obtained from pathology reports at time of surgery. All other covariates were self-reported by patients completing the telephone interview and defined as follows: race (White, African American, Other), age at menarche $(<13, \geq 13$ years), parity (nulliparous, $1-2$ births, $\geq 3$ births), age at first term pregnancy $(<26, \geq 26$ years $)$, time since last birth $(<10,10-19, \geq 20$ years), history of breastfeeding (never, ever), breastfeeding duration $(<3$, $\geq 3$ months), oral contraceptive use (never, ever), oral contraceptive duration (never, $\leq 10,>10$ years), oral contraceptive recency (never, $\leq 5,>5$ years), and menopausal hormone therapy recency (never, $\leq 5,>5$ years). Menopausal status was defined as pre- vs. postmenopausal: women with a history of bilateral oophorectomy, selfreported natural menopause, or over age 54 years (among ever smokers) or age 56 years (among non-smokers) were classified as postmenopausal, while women reporting preor perimenopausal status, having at least one intact ovary, and under age 45 years (among ever smokers) or age 47 years (among non-smokers) were classified as premenopausal. Patients who did not complete the telephone interview to assess risk factor exposure $(N=30)$ were excluded.

\section{Tissue processing and slide preparation}

All participants donated grossly normal-appearing breast tissue (as assessed by pathology assistants at UNC Hospitals) for research purposes. Tissues were snap-frozen and/or paraffin-embedded, and each patient donated between 1 and 17 specimens from grossly fibrous and mostly fat regions of the breast, as available. For breast cancer patients, tissue specimens were collected at specified distances from the tumor depending on tissue availability $(<1,>1-2,>2-4$, and $>4 \mathrm{~cm}$ ), while patients with benign breast histology donated tissue from one or two distinct breast sites as available. Frozen tissue specimens were prepared as 
described previously [16]. Briefly, $\sim 100 \mathrm{mg}$ specimens were cut over dry ice, and sections were collected at both ends of the specimen to construct two 20 micron slides per tissue specimen; 20 micron frozen sections were used to maximize tissue fidelity and image quality. All slides were H\&E stained and histological images (1-8 per patient) were scanned into high-resolution digital images using the Aperio Scan-Scope XT Slide Scanner (Aperio Technologies) in the UNC Translational Pathology Laboratory. Slides with poor resolution after scanning or significant folded tissue $(N=16)$ were manually identified and excluded from analysis. After manual review of the remaining slides by a study pathologist, four breast cancer patients were found to have tissue with high epithelial content $(>50 \%)$ that did not appear histologically normal and were excluded. Thus, the study population eligible for this analysis included 424 participants (364 patients with a confirmed diagnosis of breast cancer and 60 with no evidence of breast cancer).

\section{Assessment of breast tissue composition metrics and breast cancer risk factors}

A previously published algorithm was utilized to partition slides into epithelium, stroma, and adipose regions $[8,16$, 18, 19]. Briefly, pathologists marked areas of epithelium, stroma, adipose tissue, and total tissue area using Aperio Imagescope V11.0.2.725, enabling measurement of tissue compartment-specific areas and percentages of total area. Aperio's Genie Classifier was trained to partition epithelium, adipose tissue, nonfatty stroma, and glass (with glass excluded from the total area) with validation of test digital slides by two pathologists conducting semi-quantitative review of tissue component percentages. The results of these three methods (Genie, manual-annotation, and pathologist semi-quantitative visual review) showed strong correlations (Pearson correlation coefficients ranged 0.96-0.98), with the algorithm outperforming semiquantitative visual assessment by a pathologist and matching almost perfectly with manually annotated, pathologist reviewed images $[8,16,18,19]$. A standard, validated nuclear detection algorithm included with Genie was used to identify the number of nuclei per unit area of epithelium (defined as the general area containing terminal duct lobular units and inter-lobular ducts) and to calculate epithelial nuclear density in cells $/ \mathrm{mm}^{2}$. The algorithm calculates the density of nuclei within terminal duct lobular unit regions, and therefore handles large and small ducts similarly.

Our previous work shows that the percentages of epithelial area and age are only modestly correlated, or alternatively, that the decline is obscured because of concomitant declines in stromal area and/or total breast area [16]. However, cellular density within regions of epithelium, i.e., number of nuclei per $\mathrm{mm}^{2}$ of epithelial area, did decline with age. As a result, we focused on epithelial nuclear density as a measure of epithelial involution in the current analyses. Measures of percent stroma were considered as possible modifiers of the risk factor-epithelial nuclear density associations. We compared tissue composition measures obtained from frozen and paraffin-embedded tissue sections and found a small but significant decrease in mean percent stromal area among paraffin-embedded compared to frozen tissue specimens $(-5.2 \%, p=0.005)$. Therefore, only frozen specimens were included in our analyses, and eight patients with only paraffin-embedded samples were excluded (final $N=416$ ).

To independently validate our methods, we assessed composition metrics in a data set containing asymptomatic healthy volunteers recruited at the Mayo Clinic between 2006 and 2008. In that study, mammography and ultrasound were used to identify and sample tissue through core biopsies from regions of dense and non-dense breast tissue, as described previously [14]. The H\&E slides from the dense and non-dense paraffin-embedded tissue were subjected to our classification algorithm, with minor modifications to account for slide fading, artifacts, and differences between fixation protocols. Visual inspection showed that the modified Genie Aperio Classifier was comparable to the Normal Breast Study algorithm for identification of epithelium, adipose, non-fatty stroma and glass. Further, the Classifier correlated with prior semiquantitation of total epithelial, stromal, and adipose area (data not shown).

\section{Statistical analysis}

\section{Technical replicates}

For each tissue specimen, samples of $\sim 100 \mathrm{mg}$ size were cut and separate sections were taken from the top and bottom as described previously [16]. To compare histologic metrics within these proximal tissue sections, intraclass correlation coefficients were calculated [20], and we observed highly correlated percentage area and nuclear density measures within a small local region, implying reproducibility of our metrics [16]. Therefore, these top and bottom sections were treated as technical replicates and were averaged to create one percentage area and one nuclear density estimate per epithelial, stromal, and adipose compartment per specimen. For eight patients, one of the two replicate slides showed poor resolution after scanning; thus, histologic metrics were based on a single slide.

\section{Intraindividual variability}

To explore variability in breast composition across multiple tissue specimens from the same individual, we calculated 
Fig. 1 Distribution of stromal percentage area (a) and epithelial nuclear density according to stromal area (b) among patients in the Normal Breast Study $(N=416)$. Trend line in panel $\mathbf{b}$ obtained by linear regression, $\beta=68.2, p<0.0001$, adjusted $R^{2}=0.50$
A

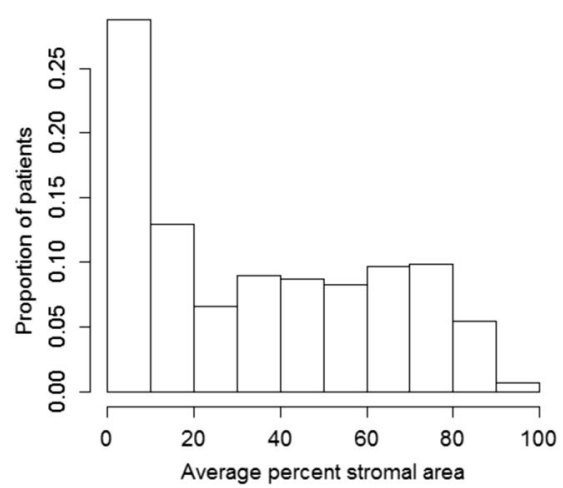

B

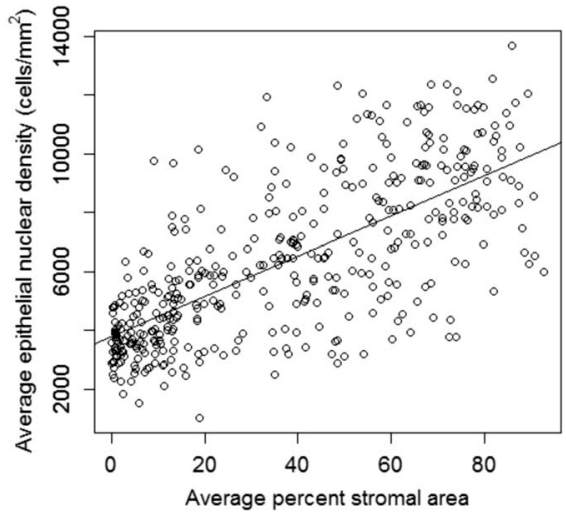

intraclass correlation coefficients and examined stromal area in a subset of patients with multiple tissue specimens from different sampling locations $(N=141)$. Again, technical replicates were averaged for each specimen. Stromal percent area was dichotomized at $10 \%$ based on visual inspection of the histogram, which suggested a rightskewed distribution of stromal area (Fig. 1a). We also anchored this $10 \%$ stroma threshold to independent observations from the Mayo data set, in which dense and nondense tissue from the same patient were sampled. A $10 \%$ stromal cutpoint could distinguish Mayo samples with high mammographic density (BI-RADS categories 3 and 4) from those without, with $91 \%$ sensitivity and $85 \%$ specificity (Table 1). Thus, independent data suggest a $10 \%$ stromal area threshold may be biologically meaningful. Based on these observations, we categorized specimens according to stromal area as follows: all replicate biological samples $\geq 10 \%$ stroma, all samples $<10 \%$ stroma, or mixed, referred to henceforth as "adequate stroma", "mostly fat", and "mixed", respectively. Polytomous logistic regression was used to relate patient and sampling factors (e.g., number of tissue samples, age, and mammographic density) to stromal area among women with multiple tissue samples $(N=141)$.

Table 1 Assessment of sensitivity and specificity using different stromal area cutpoints in Mayo data set $(N=150$ samples, 75 dense/ nondense tissue pairs)

\begin{tabular}{lllll}
\hline & $\begin{array}{l}\text { Non-dense } \\
(N=75)\end{array}$ & $\begin{array}{l}\text { Dense }(N \\
=75)\end{array}$ & Sensitivity & Specificity \\
\hline $\begin{array}{l}\text { Stromal area } \\
\text { cutpoint }\end{array}$ & & & & \\
$<5 \%$ & 53 & 3 & & \\
$\geq 5 \%$ & 22 & 72 & 96.0 & 70.7 \\
$<10 \%$ & 64 & 7 & & \\
$\geq 10 \%$ & 11 & 68 & 90.7 & 85.3 \\
$<15 \%$ & 69 & 16 & & \\
$\geq 15 \%$ & 6 & 56 & 77.8 & 92.0 \\
\hline
\end{tabular}

\section{Risk factor associations with tissue composition}

For analyses assessing associations between histology and risk factor exposure, a single specimen was evaluated for each patient. For patients with "adequate stroma" samples, the first sampled tissue site with adequate stroma was selected; for patients with all "mostly fat" specimens, the specimen closest to tumor or first sampled specimen was included. Linear regression was used to estimate associations between breast cancer risk factors and epithelial nuclear density among all women $(N=416)$. All risk factors were modeled categorically using indicator terms, and linear tests for trend were conducted for continuous exposures showing a linear dose-response relationship with epithelial nuclear density (age, body mass index, and mammographic density). Univariate analyses estimated unadjusted associations between each risk factor and epithelial nuclear density, while multivariate analyses were adjusted for continuous age and type of surgery (canceradjacent lumpectomy/mastectomy, reduction mammoplasty/prophylactic mastectomy, and benign biopsy), as these factors were found to be associated with stromal content. Patients were not excluded on the basis of disease status, as sensitivity analyses reported previously [16] suggested results were similar when excluding patients without breast cancer. All risk factor analyses were stratified by stromal area (10\% cutpoint), and heterogeneity of stratified estimates was compared to assess effect measure modification. Cubic spline models and boxplots were used to visualize the relationships between age or menopausal status and epithelial nuclear density overall and by stromal area. Spline models specified a knot at age 55 years consistent with evidence of an inflection point. Statistical significance for all analyses was defined as $p<0.05$, and statistical analyses were performed using SAS software, version 9.4 (SAS Institute, Inc., Cary, North Carolina), or $\mathrm{R}$, version 3.2.3 (for spline models). 


\section{Results}

\section{Intraindividual variability in breast stromal area}

The stromal area showed a right-skewed distribution (Fig. 1a, b) in this study, with $\sim 24 \%$ of samples having $<10 \%$ stromal area. Among 408 women with repeated breast tissue sampling, the majority of women $(81 \%)$ had at least one sample with at least $10 \%$ stroma, with $51 \%$ of all women having stromal area $\geq 10 \%$ for all specimens. We observed substantial intraindividual variation in the levels of stromal area across samples; Fig. 2 illustrates differences in stromal area for four representative women with repeated sampling. Intraclass correlations comparing tissue specimens from two distinct sampling sites from 141 women revealed low consistency in stromal percent area and epithelial nuclear density across different breast regions (stroma: $0.44,95 \%$ CI: 0.32, 0.54; epithelium: 0.35, 95\% CI: $0.23,0.47)$. Interestingly, premenopausal women with mostly fat samples were common (35\% of premenopausal women), and many patients (25\% overall) had both low stroma $(<10 \%)$ and higher stroma $(\geq 10 \%)$ samples within the same breast. These results highlight substantial intraindividual variability in breast composition across women of all ages.

To identify factors contributing to sampling reproducibility, patients were divided into three groups: all samples $\geq 10 \%$ stroma (adequate stroma), all samples $<10 \%$ stroma (mostly fat), and mixed. Examining whether breast quadrant was related to intraindividual variability in stromal area revealed a slightly higher likelihood of mixed stroma/ mostly fat tissue samples among women with upper outer quadrant sampling compared to other quadrants, though no associations were statistically significant and the precision of our effect estimates was poor (results not shown). However, the number of tissue samples greatly increased the odds of having mixed class, while women with all mostly fat samples tended to have fewer samples (Table 2). Women with mixed composition tended to be older with lower mammographic density than women who had consistently adequate (at least 10\%) stromal composition. Sampling and patient characteristics appeared to significantly influence both the magnitude and intraindividual variability of stromal area.

\section{Stromal area modifies the dynamic range of epithelial nuclear density}

The distribution of epithelial nuclear density comparing low stroma $(<10 \%)$ to higher stroma (at least $10 \%)$ revealed marked differences in the range of epithelial nuclear density values (Fig. 3a). Low stroma was associated with low average epithelial nuclear density (mean $=3910.8$ cells/ $\mathrm{mm}^{2}, \mathrm{SE}=117.4$ cells $/ \mathrm{mm}^{2}$ ) and little variability across patients. In contrast, the mean and dynamic range of epithelial nuclear density were dramatically greater for samples with adequate stroma (stromal area $\geq 10 \%$ ), encompassing approximately twice the range of nuclear density values $\left(\right.$ mean $=7077.6$ cells $/ \mathrm{mm}^{2}, \mathrm{SE}=145.2$ cells $\left./ \mathrm{mm}^{2}\right)$. Moreover, patterns of age-dependent involution were evident only in samples with at least $10 \%$ stroma (Fig. 3b). Among those with adequate stroma $(\geq 10 \%)$, epithelial nuclear density remained relatively stable at $\sim 8000$ cells $/ \mathrm{mm}^{2}$ until age 55 years, after which epithelial nuclear density declined rapidly at a rate of $99.7 \mathrm{cells} / \mathrm{mm}^{2}$ per year $(p<0.0001)$. In contrast, women with low stroma samples $(<10 \%)$ had tissue that appeared to be completely involuted, with epithelial nuclear density remaining stable at $\sim 4000$ cells $/ \mathrm{mm}^{2}$ and showing no change with increasing age. For comparison with previous studies that did not stratify on stromal content, we also performed analyses considering all samples, wherein epithelial nuclear density decreased with age at an annual rate of 39.1 cells $/ \mathrm{mm}^{2}(p=0.04)$ until age 55 years, after which the rate increased and epithelial nuclear density declined 66.5 cells $/ \mathrm{mm}^{2}$ per year $(p=0.0008)$ (Fig. 3b). There was high variability within stromal area categories $\left(R^{2}<0.1\right)$ underscoring the importance of replicate observations and large samples sizes in histologic studies of normal breast.

\section{Risk factor associations with epithelial nuclear density are influenced by stromal area}

Given the observation that epithelial involution status is associated with stromal composition, we hypothesized that risk factor associations with epithelial involution may be modified by stromal content. Indeed, exclusion of samples containing low stroma showed different and stronger risk factor associations with epithelial nuclear density than those among women overall (Table 3). Among women with low stromal area, no risk factors were significantly associated with epithelial nuclear density (Table 4). However, among patients with high stroma (Table 3), we observed significant associations with risk factor exposures.

Epithelial nuclear density significantly varied by surgery type after adjustment for age, with women receiving reduction mammoplasties or prophylactic mastectomies having significantly lower epithelial nuclear density than women receiving surgeries related to their cancer diagnosis (difference $=-891.1$ cells $/ \mathrm{mm}^{2}, p=0.03$ ); thus, all subsequent analyses adjusted for surgery type. Postmenopausal women appeared to have dramatically lower epithelial nuclear density in univariate analyses $(p<0.0001)$, but not after adjusting for age and surgery type $(p=0.5)$. Among women with stromal area $\geq 10 \%$, higher mammographic density was associated with significantly increased 
Fig. 2 Intraindividual variation in breast tissue composition across repeated tissue sampling. Panels a1-d2 represent $\mathrm{H} \& \mathrm{E}$ slides taken at resolution $\times 2$ from four representative women in the Normal Breast Study (two slides per woman) highlighting differences in tissue composition across distinct regions of the breast. Images from panels a1/ $\mathbf{a} 2$ and $\mathbf{b} 1 / \mathbf{b} 2$ represent tissue from a 58-year-old and 39-yearold woman, respectively, with mixed adequate stroma/mostly fat tissue samples. Images from panels $\mathbf{c} 1 / \mathbf{c} 2$ and $\mathbf{d} 1 / \mathbf{d} 2$ represent tissue from a 38 -year-old and 64-year-old woman, respectively, with all adequate stroma tissue samples

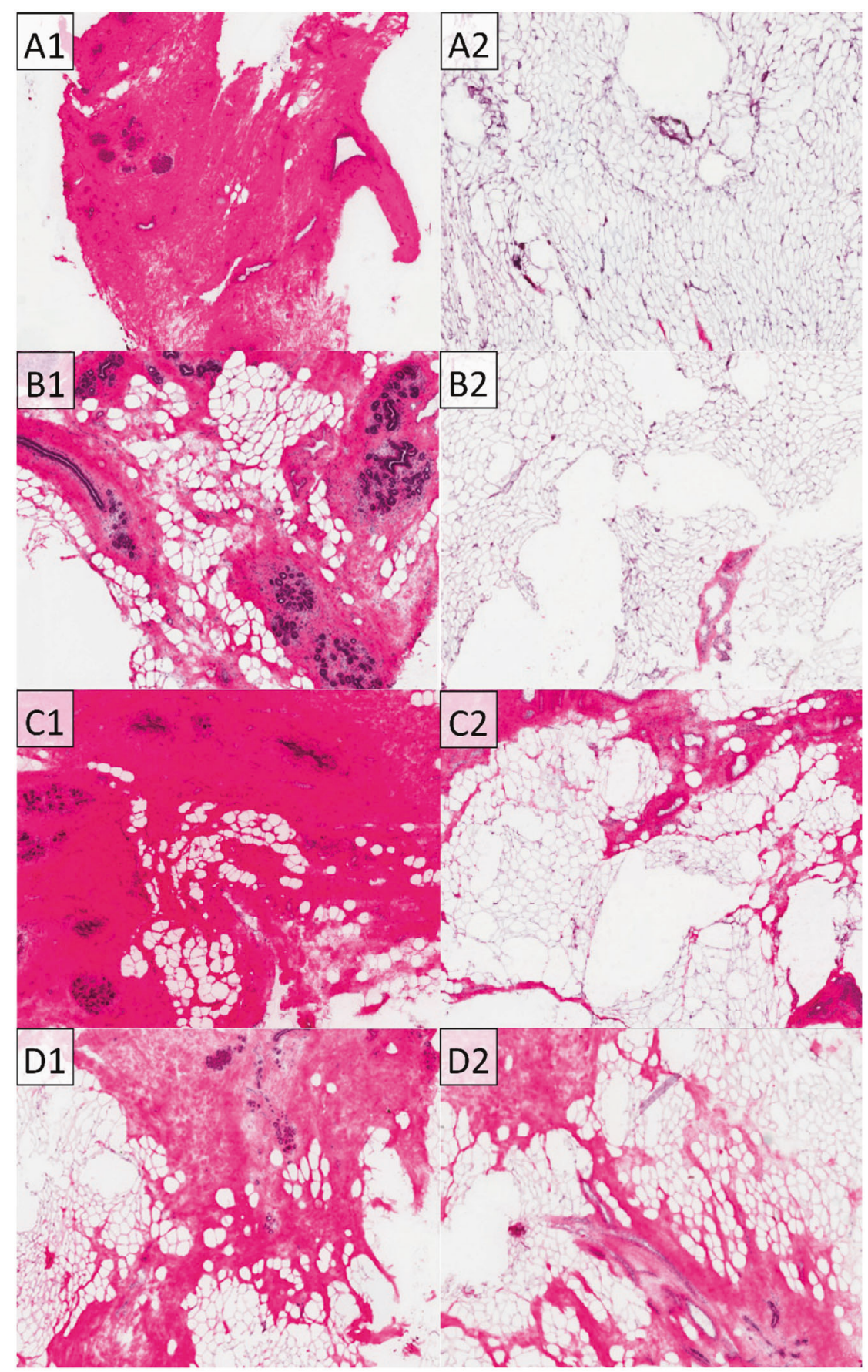

epithelial nuclear density in adjusted models (Table 3). Epithelial nuclear density was significantly higher among women with later age at first term pregnancy, more recent birth, longer durations of oral contraceptive use ( $>10$ years), and more recent use of oral contraceptives ( $\leq 5$ years ago) in univariate analyses (results not shown). These associations were attenuated and not significant in adjusted models, but the patterns of association were still consistent (Table 3). Race, body mass index, age at menarche, history of breastfeeding, breastfeeding duration, and menopausal hormone therapy recency were not associated with epithelial nuclear density.

\section{Discussion}

Understanding the relationship between risk factors and breast histology may inform breast cancer risk assessment [7-10]. Our findings suggest that epithelial nuclear density is sensitive to some risk factor exposures. Higher epithelial 
Table 2 Patient factors contributing to intraindividual variability of stromal area within women with multiple tissue specimens in the Normal Breast Study $(N=141)$

\begin{tabular}{|c|c|c|c|c|c|}
\hline & \multirow{2}{*}{$\begin{array}{l}\text { All adequate } \text { stroma }^{\mathrm{a}}(N=57) \\
N(\%)\end{array}$} & \multicolumn{2}{|c|}{$\begin{array}{l}\text { Mixed stroma/mostly fat }{ }^{\mathrm{a}}(N= \\
58)\end{array}$} & \multicolumn{2}{|c|}{ All mostly fat ${ }^{\mathrm{a}}(N=16)$} \\
\hline & & $N(\%)$ & OR $(95 \%$ CI) & $N(\%)$ & OR $(95 \% \mathrm{CI})$ \\
\hline \multicolumn{6}{|l|}{ Sample number } \\
\hline Mean \pm standard deviation & $6.6 \pm 2.8$ & $7.9 \pm 3.6$ & & $5.8 \pm 2.3$ & \\
\hline Linear trend estimate & & & $1.14(p=0.03)$ & & $0.90(p=0.3)$ \\
\hline \multicolumn{6}{|l|}{ Age } \\
\hline Mean \pm standard deviation & $52.2 \pm 11.7$ & $60.0 \pm 12.0$ & & $56.5 \pm 11.8$ & \\
\hline Linear trend estimate & & & $1.06(p=0.001)$ & & $1.03(p=0.2)$ \\
\hline \multicolumn{6}{|l|}{ Mammographic density ${ }^{b}$} \\
\hline BIRADS 1/2 (ref) & $12(22.6)$ & $31(56.4)$ & 1.0 & $11(68.8)$ & 1.0 \\
\hline BIRADS $3 / 4$ & $41(77.4)$ & $24(43.6)$ & $0.23(0.10,0.52)$ & $5(31.3)$ & $0.13(0.04,0.46)$ \\
\hline Missing & 4 & 3 & & 3 & \\
\hline
\end{tabular}

${ }^{a}$ Adequate stroma samples defined as $\geq 10 \%$ stromal area; mostly fat samples defined as $<10 \%$ stromal area

${ }^{b}$ BIRADS $1 / 2$ includes fatty and scattered fibroglandular densities categories; BIRADS 3/4 includes heterogeneously and extremely dense categories

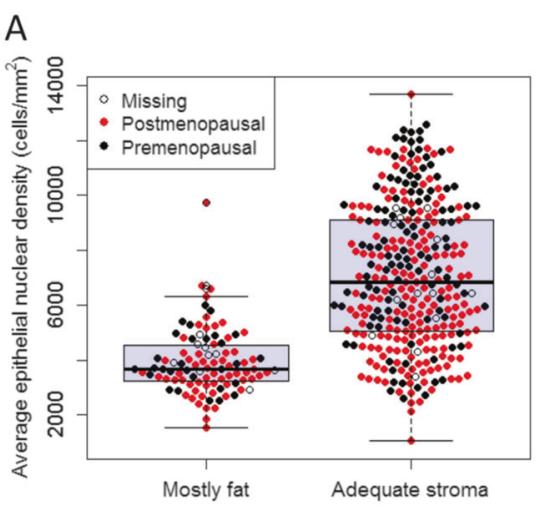

Fig. 3 Epithelial nuclear density by stromal area content in the Normal Breast Study $(N=416)$. a Distribution of epithelial nuclear density by stromal area among pre- and postmenopausal women in the Normal Breast Study. "Mostly fat" denotes tissue samples with $<10 \%$ stromal area while "adequate stroma" denotes samples with $\geq 10 \%$ stromal area.

cell content (i.e., nuclear density) was associated with higher mammographic density, and, to a lesser extent, with later age at first term pregnancy, more recent time since last birth, and longer duration and more recent use of oral contraceptives. However, these associations were evident only in samples with higher (at least 10\%) stromal percent area. There was substantial intraindividual variability in stromal percent area in our study, underscoring the need for systematic sampling strategies. The probability of sampling a tissue specimen with at least $10 \%$ stromal area was increased with younger age, lower body mass index, higher mammographic density, and greater number of tissue samples.

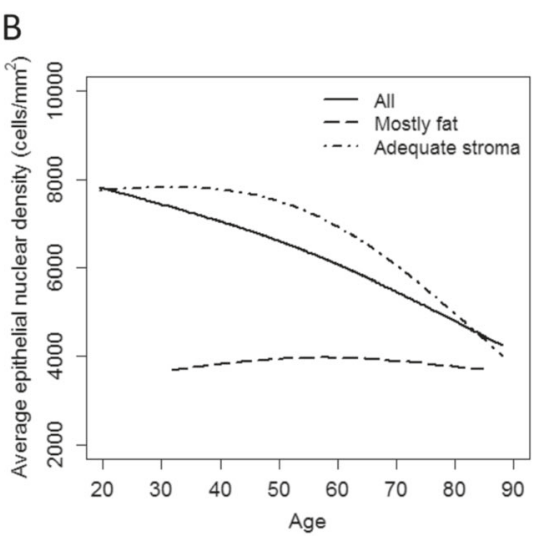

b Cublic spline curves for epithelial nuclear density by age stratified by stromal area (inflection point at age 55 years). $R^{2}=0.02,0.09$, and 0.06 for "mostly fat", "adequate stroma", and "all" spline curves, reflecting high variability between categories

Previous studies have also assessed intraindividual variability in breast composition. Hutson et al. [13] described variability in the representation of epithelium but similarities in lobule size and composition across different breast quadrants, while Figueroa et al. [9] observed mixed adipose content in breast tissue samples. Gierach et al. [5] identified moderate agreement in the number of terminal duct lobular units, a measure of breast involution, within replicate breast biopsies, but observed heterogeneity in measures of terminal duct lobular unit size among premenopausal women. In contrast, Vierkant et al. [12], among others $[1,6]$, identified little heterogeneity in markers of breast involution (including involution of terminal duct 
Table 3 Risk factor associations with epithelial nuclear density among women overall and with adequate stroma (stromal area $\geq 10 \%$ ) breast tissue

\begin{tabular}{|c|c|c|c|c|c|c|c|c|}
\hline & \multicolumn{4}{|c|}{ All patients $(N=416)$} & \multicolumn{4}{|c|}{ Adequate stroma (stromal area $\geq 10 \% ; N=317$ ) } \\
\hline & $N$ & $\begin{array}{l}\text { Mean (standard } \\
\text { error) }\end{array}$ & $\begin{array}{l}\text { Difference (standard } \\
\text { error) }{ }^{\mathrm{a}}\end{array}$ & $p$ & $N$ & $\begin{array}{l}\text { Mean (standard } \\
\text { error) }\end{array}$ & $\begin{array}{l}\text { Difference (standard } \\
\text { error) })^{\mathrm{a}}\end{array}$ & $p$ \\
\hline \multicolumn{9}{|l|}{ Age } \\
\hline$<50$ years & 158 & $6921.0(228.3)$ & Ref & & 127 & $7702.2(234.6)$ & Ref & \\
\hline$\geq 50$ years & 258 & $5958.3(156.3)$ & $-1056.1(274.7)$ & 0.0001 & 190 & $6660.0(178.9)$ & $-1137.0(299.2)$ & 0.0001 \\
\hline \multicolumn{9}{|l|}{ Race } \\
\hline White (ref) & 274 & $6386.7(163.6)$ & Ref & & 210 & $7121.7(179.5)$ & Ref & \\
\hline African American & 111 & $6013.4(245.6)$ & $-579.4(291.7)$ & 0.05 & 81 & $6878.7(274.3)$ & $-441.5(322.9)$ & 0.2 \\
\hline Other & 31 & $6881.3(510.3)$ & $-82.4(497.4)$ & 0.9 & 26 & $7340.5(562.2)$ & $-353.5(519.6)$ & 0.5 \\
\hline \multicolumn{9}{|l|}{ Body mass index $\left(\mathrm{kg} / \mathrm{m}^{2}\right)$} \\
\hline$<25.0$ (ref) & 156 & $6921.5(221.7)$ & Ref & & 135 & $7392.7(225.2)$ & Ref & \\
\hline $25.0-29.9$ & 83 & $6250.0(280.9)$ & $-467.1(352.4)$ & 0.2 & 64 & $6935.6(306.9)$ & $-280.8(377.5)$ & 0.5 \\
\hline$\geq 30.0$ & 177 & $5831.9(194.5)$ & $-928.8(281.8)$ & 0.001 & 118 & $6794.0(239.4)$ & $-440.4(310.9)$ & 0.2 \\
\hline Trend test $\beta$ & & & $-67.3(18.8)$ & 0.0004 & & & $-38.7(21.8)$ & 0.08 \\
\hline \multicolumn{9}{|l|}{ Mammographic density } \\
\hline 1-Fatty (ref) & 34 & 4489.5 (272.6) & Ref & & 15 & $5246.0(503.8)$ & Ref & \\
\hline $\begin{array}{l}\text { 2-Scattered } \\
\text { fibroglandular }\end{array}$ & 148 & $5496.2(195.6)$ & $1061.9(478.5)$ & 0.03 & 97 & $6202.4(253.1)$ & $1175.9(671.1)$ & 0.08 \\
\hline $\begin{array}{l}\text { 3-Heterogeneously } \\
\text { dense }\end{array}$ & 153 & 7110.9 (229.7) & $2379.2(482.3)$ & $<0.0001$ & 128 & $7814.1(225.1)$ & 2353.7 (659.8) & 0.0004 \\
\hline 4-Extremely dense & 15 & $6879.2(653.6)$ & $1860.7(775.5)$ & 0.02 & 15 & $6879.2(653.6)$ & $1069.1(877.8)$ & 0.2 \\
\hline Dense, NOS & 33 & 7405.1 (459.9) & $2872.4(613.0)$ & $<0.0001$ & 32 & $7530.0(456.6)$ & 2333.7 (753.9) & 0.002 \\
\hline Missing & 33 & & & & 30 & & & \\
\hline Trend test $\beta$ & & & $736.4(130.0)$ & $<0.0001$ & & & $457.8(144.6)$ & 0.002 \\
\hline \multicolumn{9}{|l|}{ Age at menarche } \\
\hline$<13$ years (ref) & 202 & $6260.4(194.1)$ & Ref & & 145 & $7,227.3(214.7)$ & Ref & \\
\hline$\geq 13$ years & 213 & $6398.0(180.0)$ & $322.3(255.6)$ & 0.2 & 172 & $6951.3(197.2)$ & $-33.6(281.1)$ & 0.9 \\
\hline Missing & 1 & & & & 0 & & & \\
\hline \multicolumn{9}{|l|}{ Parity } \\
\hline Nulliparous (ref) & 68 & 6537.5 (309.5) & Ref & & 55 & 7153.8 (325.9) & Ref & \\
\hline $1-2$ births & 240 & $6508.8(177.4)$ & $303.6(360.7)$ & 0.4 & 188 & $7201.0(192.8)$ & $475.6(385.6)$ & 0.2 \\
\hline$\geq 3$ births & 108 & $5778.5(249.1)$ & $-241.9(413.2)$ & 0.6 & 74 & $6707.1(297.0)$ & $121.9(453.3)$ & 0.8 \\
\hline \multicolumn{9}{|c|}{ Age at first term pregnancy ${ }^{b}$} \\
\hline$<26$ years (ref) & 206 & $5955.7(181.6)$ & Ref & & 149 & $6785.6(209.3)$ & Ref & \\
\hline$\geq 26$ years & 142 & $6755.9(236.1)$ & $547.7(288.1)$ & 0.06 & 113 & $7425.4(252.1)$ & $318.2(315.1)$ & 0.3 \\
\hline \multicolumn{9}{|l|}{ Time since last birth ${ }^{\mathrm{b}}$} \\
\hline$<10$ years (ref) & 51 & $7715.8(426.3)$ & Ref & & 44 & $8344.2(419.3)$ & Ref & \\
\hline $10-19$ years & 81 & $6501.6(308.3)$ & $-786.4(491.1)$ & 0.1 & 61 & $7340.1(338.1)$ & $-454.7(520.0)$ & 0.4 \\
\hline$\geq 20$ years & 215 & $5867.9(170.3)$ & $-780.0(581.0)$ & 0.2 & 157 & $6593.8(195.3)$ & $-266.8(645.8)$ & 0.7 \\
\hline Missing & 1 & & & & 0 & & & \\
\hline \multicolumn{9}{|l|}{ History of breastfeeding ${ }^{\mathrm{b}}$} \\
\hline Never (ref) & 158 & $5968.4(204.5)$ & Ref & & 113 & $6789.4(239.8)$ & Ref & \\
\hline Ever & 190 & $6543.1(204.1)$ & $257.9(288.2)$ & 0.4 & 149 & $7267.9(218.6)$ & $98.6(320.4)$ & 0.8 \\
\hline \multicolumn{9}{|l|}{ Breastfeeding duration $^{\mathrm{b}}$} \\
\hline$<3$ months (ref) & 208 & $6076.3(180.5)$ & Ref & & 150 & $6919.0(208.2)$ & Ref & \\
\hline$\geq 3$ months & 140 & $6588.1(241.8)$ & $197.0(292.0)$ & 0.5 & 112 & $7252.5(256.8)$ & $-54.7(319.0)$ & 0.9 \\
\hline
\end{tabular}


Table 3 (continued)

\begin{tabular}{|c|c|c|c|c|c|c|c|c|}
\hline & \multicolumn{4}{|c|}{ All patients $(N=416)$} & \multicolumn{4}{|c|}{ Adequate stroma (stromal area $\geq 10 \% ; N=317$ ) } \\
\hline & $N$ & $\begin{array}{l}\text { Mean (standard } \\
\text { error) }\end{array}$ & $\begin{array}{l}\text { Difference (standard } \\
\text { error) }{ }^{\mathrm{a}}\end{array}$ & $p$ & $N$ & $\begin{array}{l}\text { Mean (standard } \\
\text { error) }\end{array}$ & $\begin{array}{l}\text { Difference (standard } \\
\text { error) }^{\mathrm{a}}\end{array}$ & $p$ \\
\hline \multicolumn{9}{|c|}{ Oral contraceptive duration } \\
\hline Never (ref) & 69 & $6120.6(326.1)$ & Ref & & 57 & $6552.7(363.4)$ & Ref & \\
\hline$\leq 10$ years & 258 & $6190.6(164.4)$ & $-290.9(356.0)$ & 0.4 & 189 & $7015.3(184.8)$ & $116.5(377.2)$ & 0.8 \\
\hline$>10$ years & 87 & $6874.7(297.9)$ & $341.7(421.7)$ & 0.4 & 70 & $7644.0(299.6)$ & $686.5(444.2)$ & 0.1 \\
\hline Missing & 1 & & & & 1 & & & \\
\hline \multicolumn{9}{|c|}{ Oral contraceptive recency } \\
\hline Never (ref) & 69 & $6120.6(326.1)$ & Ref & & 57 & $6552.7(363.4)$ & Ref & \\
\hline$\leq 5$ years ago & 57 & $7571.8(367.5)$ & $478.2(517.7)$ & 0.4 & 49 & $8218.7(345.2)$ & $750.5(535.5)$ & 0.2 \\
\hline$>5$ years ago & 288 & $6120.0(153.5)$ & $-194.2(348.6)$ & 0.6 & 210 & $6938.7(173.2)$ & $204.5(368.6)$ & 0.6 \\
\hline Missing & 2 & & & & 1 & & & \\
\hline \multicolumn{9}{|c|}{ Menopausal hormone therapy recency ${ }^{\mathrm{c}}$} \\
\hline Never (ref) & 140 & $5925.0(226.3)$ & Ref & & 106 & $6579.1(257.5)$ & Ref & \\
\hline$\leq 5$ years ago & 54 & $6166.3(348.3)$ & $323.6(396.0)$ & 0.4 & 41 & $6974.0(363.9)$ & $336.5(432.4)$ & 0.4 \\
\hline$>5$ years ago & 49 & $5590.0(311.1)$ & $-38.6(415.0)$ & 0.9 & 35 & $6233.4(373.0)$ & $48.3(462.3)$ & 0.9 \\
\hline Missing & 4 & & & & 4 & & & \\
\hline
\end{tabular}

lobular units and lobules as well as differences in lobule type) across multiple breast tissue specimens obtained from the same woman. Differences between these studies may reflect differences in how sampling was performed. In many studies, breast tissue sampling occurs by pathologist gross assessment of tissue specimens [1, 2, 6, 8, 12, 13, 21, 22] or by mammography- and ultrasound-guided sampling [10, 14], either of which may result in oversampling of dense, high stromal-content tissues. Our study pathologists were instructed to sample both grossly fibrous and mostly fat regions of breast, and therefore our study was sensitive to uncovering intraindividual variability. Similarly, the study by Mayo included in the present report explicitly sampled high- and low-density areas and showed similar intraindividual variability in stromal content. Other sampling strategies may explicitly or implicitly favor sampling of epithelial-rich areas and therefore may have lower risk of sampling low stroma tissue. However, our findings demonstrate conclusively that sampling strategy, and specifically stromal composition, has important implications for risk factor and histologic associations.

Previous experimental studies have documented the importance of stroma and the breast microenvironment in regulating epithelium. In experimental and model systems, stroma plays a critical role in mammary gland development, growth of epithelium, and tumorigenesis [23-25]. In the current study with human tissues, the limited dynamic range of epithelial nuclear density within regions of low stromal area suggests stroma is also important in maintaining human breast epithelium. We hypothesized that if a gland is fully involuted and/or lacks stroma for active regulation, it may be less responsive to other hormonal factors and risk factorinduced changes. Indeed, tissue with stromal area $\geq 10 \%$ showed the strongest associations between epithelial nuclear density and risk factor exposures. Stroma-poor regions of the breast may lack regulation mechanisms present in stroma-rich regions.

Some of the associations we observed among samples with high stroma have been reported previously. It is well established that both stromal and epithelial content are associated with higher mammographic density [8, 10, 14, $26,27]$. In fact, mammographic density is often interpreted as a noninvasive measure of fibroglandular content, underscoring that fibrous stroma and epithelial glandular tissue cannot be readily distinguished in mammograms. Our data emphasize that stromal content may itself be associated with higher epithelial content, suggesting a plausible explanation for why percent density and mammographically dense area both have strong associations with risk [2, 27]. Although we were underpowered to study associations using multivariate logistic regression in the Mayo dataset, those data provided independent validation of the association between stromal content and dense area as identified through breast imaging, demonstrating that both parameters vary intraindividually. Taken together, these findings show that mammographically dense area reflects variability in 
Table 4 Risk factor associations with epithelial nuclear density among women with mostly fat (stromal area $<10 \%)$ breast tissue $(N=99)$

\begin{tabular}{|c|c|c|c|c|}
\hline & $N$ & Mean (standard error) & Difference (standard error) ${ }^{\mathrm{a}}$ & $p$ \\
\hline \multicolumn{5}{|l|}{ Age } \\
\hline$<50$ years & 31 & $3720.5(133.7)$ & & \\
\hline$\geq 50$ years & 68 & $3997.5(159.3)$ & & \\
\hline \multicolumn{5}{|l|}{ Race } \\
\hline White (ref) & 64 & $3974.8(159.9)$ & Ref & \\
\hline African American & 30 & $3677.0(167.5)$ & $-311.1(261.1)$ & 0.2 \\
\hline Other & 5 & $4493.3(370.3)$ & $506.4(544.9)$ & 0.4 \\
\hline \multicolumn{5}{|l|}{ Body mass index $\left(\mathrm{kg} / \mathrm{m}^{2}\right)$} \\
\hline$<25.0$ (ref) & 21 & $3892.3(340.0)$ & Ref & \\
\hline 25.0 to 29.9 & 19 & $3940.6(275.4)$ & $55.8(385.5)$ & 0.9 \\
\hline$\geq 30.0$ & 59 & 3907.7 (131.6) & $22.4(298.5)$ & 0.9 \\
\hline Trend test $\beta$ & & & $-8.7(16.7)$ & 0.6 \\
\hline \multicolumn{5}{|l|}{ Mammographic density } \\
\hline 1-Fatty (ref) & 19 & $3892.3(207.6)$ & Ref & \\
\hline 2-Scattered fibroglandular & 51 & $4153.1(193.2)$ & $263.4(326.1)$ & 0.4 \\
\hline 3-Heterogeneously dense & 25 & $3510.4(158.8)$ & $-390.8(377.6)$ & 0.3 \\
\hline 4-Extremely dense & $X^{b}$ & - & - & \\
\hline Dense, NOS & $\mathrm{X}^{\mathrm{b}}$ & - & - & \\
\hline Missing & 3 & & & \\
\hline \multicolumn{5}{|l|}{ Age at menarche } \\
\hline$<13$ years (ref) & 57 & $3800.7(164.1)$ & Ref & \\
\hline$\geq 13$ years & 41 & $4077.1(167.1)$ & $284.0(238.7)$ & 0.2 \\
\hline Missing & 1 & & & \\
\hline \multicolumn{5}{|l|}{ Parity } \\
\hline Nulliparous (ref) & 13 & $3929.8(273.8)$ & Ref & \\
\hline $1-2$ births & 52 & $4006.2(177.0)$ & $72.1(362.4)$ & 0.8 \\
\hline$\geq 3$ births & 34 & $3757.5(183.4)$ & $-188.3(389.1)$ & 0.6 \\
\hline \multicolumn{5}{|l|}{ Age at first term pregnancy ${ }^{c}$} \\
\hline$<26$ years $($ ref $)$ & 57 & $3786.4(132.5)$ & Ref & \\
\hline$\geq 26$ years & 29 & $4146.8(279.7)$ & $358.4(271.3)$ & 0.2 \\
\hline \multicolumn{5}{|l|}{ Time since last birth ${ }^{\mathrm{c}}$} \\
\hline$<10$ years (ref) & 7 & $3765.9(320.3)$ & Ref & \\
\hline $10-19$ years & 20 & $3943.9(251.6)$ & $256.3(553.0)$ & 0.6 \\
\hline$\geq 20$ years & 58 & $3902.8(167.9)$ & $273.5(575.1)$ & 0.6 \\
\hline Missing & 1 & & & \\
\hline \multicolumn{5}{|l|}{ History of breastfeeding ${ }^{c}$} \\
\hline Never (ref) & 45 & $3906.7(146.1)$ & Ref & \\
\hline Ever & 41 & $3909.2(220.6)$ & $-7.9(259.3)$ & 1.0 \\
\hline \multicolumn{5}{|l|}{ Breastfeeding duration $^{c}$} \\
\hline$<3$ months (ref) & 58 & $3896.9(124.6)$ & Ref & \\
\hline$\geq 3$ months & 28 & 3930.7 (305.9) & $26.3(276.4)$ & 0.9 \\
\hline \multicolumn{5}{|l|}{ Oral contraceptive duration } \\
\hline Never (ref) & 12 & $4068.4(350.1)$ & Ref & \\
\hline$\leq 10$ years & 69 & $3931.7(144.7)$ & $-154.4(377.7)$ & 0.7 \\
\hline$>10$ years & 17 & $3706.9(260.0)$ & $-384.8(449.6)$ & 0.4 \\
\hline Missing & 1 & & & \\
\hline
\end{tabular}


Table 4 (continued)

\begin{tabular}{|c|c|c|c|c|}
\hline & $N$ & Mean (standard error) & Difference (standard error) $^{\mathrm{a}}$ & $p$ \\
\hline \multicolumn{5}{|c|}{ Oral contraceptive recency } \\
\hline Never (ref) & 12 & $4068.4(350.1)$ & Ref & \\
\hline$\leq 5$ years ago & 8 & $3609.8(293.4)$ & $-628.7(608.6)$ & 0.3 \\
\hline$>5$ years ago & 78 & $3915.7(136.4)$ & $-203.8(371.6)$ & 0.6 \\
\hline Missing & 1 & & & \\
\hline \multicolumn{5}{|c|}{ Menopausal hormone therapy recency ${ }^{\mathrm{d}}$} \\
\hline Never (ref) & 34 & $3885.6(253.6)$ & Ref & \\
\hline$\leq 5$ years ago & 13 & $3618.7(348.0)$ & $-156.7(430.0)$ & 0.7 \\
\hline$>5$ years ago & 14 & $3981.4(249.1)$ & $41.6(424.8)$ & 0.9 \\
\hline
\end{tabular}

${ }^{a}$ Adjusted for age and surgery type (surgery type model adjusted only for age, age model adjusted only for surgery type)

${ }^{\mathrm{b}}$ Cells with fewer than five patients were suppressed to maintain patient confidentiality

${ }^{\mathrm{c}}$ Among parous women

${ }^{\mathrm{d} A m o n g}$ postmenopausal women

composition across the entire breast, and our study shows this intraindividual variability to be quite high.

Consistent with our findings, most studies examining breast epithelial content in relation to parity and other reproductive or hormone exposures (including age at first term pregnancy, breastfeeding history, and oral contraceptive use) have observed no long-term statistically significant differences in epithelial content with exposure [7, 8, 10]. Jindal et al. [28] and Russo et al. [6] reported increased epithelial area and lobule formation, respectively, during pregnancy and significant epithelial regression postpartum, but these changes were transient and were offset by postpartum involution. In contrast, we found increased epithelial nuclear density among recently parous women and recent or long-term users of oral contraceptives, similar to a study of epithelial percent area by Gertig et al. [7]. The effects of parity and other risk factors may vary in study populations according to methodological and selection factors.

Our findings should be interpreted in light of some limitations. Our study included histologically normal breast tissue sampled from women undergoing breast surgery due to cancer or other benign conditions. Although biopsy and mastectomy samples minimize risks to patients and are therefore most commonly used in previous breast histology studies [1, 6-9, 12,14, 16, 18, 19, 21, 22], there is potential for reverse causation and selection bias, with more women participating with epithelial and/or stroma-rich tissue. Indeed, we found that epithelial nuclear density varied by procedure. However, we observed associations that were comparable to those from other studies including only volunteers with benign or healthy breast tissue [7, 9]. It has also been suggested that breast tissue response to hormone exposure may be stronger in high-risk women [29]. Thus, while some associations we detect may be different in a general population, they may be highly relevant for a susceptible group of high-risk women. Additionally, we did not use specific multivariable modeling strategies to adjust for repeated tissue samplings in our study. Rather, we selected one sampling site for inclusion in our analyses to most closely approximate the previous literature which used one sample per patient. While a strength of our study is the use of frozen tissue which avoids artifacts and cell shrinkage associated with formalin-fixed paraffin-embedded tissues, paraffin-embedded samples are more highly represented in breast tissue studies, which may complicate the comparison of findings across preservation types. However, our validation to the Mayo test data set involving paraffin-embedded samples showed that algorithm performance was comparable to the Normal Breast Study algorithm, suggesting that future comparisons may reveal similar patterns of breast tissue composition regardless of preservation method. We also did not distinguish between luminal epithelium and myoepithelium in our measure of epithelial nuclear density, and we may have occasionally misclassified endothelial and epithelial cells due to similarities between the size of nuclei and architecture of the lumen. We were unable to evaluate how tissue histology related to patient germline genetics, immune infiltrates, or physiological changes in breast tissue associated with menstrual cycling, all of which would be interesting future directions for studies of benign breast tissue. Finally, while our study included over 400 women, our analyses of some risk factors were undoubtedly underpowered given the high variation within and across participants. Larger studies with repeated sampling of the same individuals may identify subtler patterns in breast tissue composition across breast cancer risk factors.

In summary, our findings underscore the importance of stroma in modifying epithelial characteristics of breast tissue and indicate that both sampling strategies and analysis 
methods for breast tissue should consider epithelial and stromal components simultaneously. There is widespread interest in using epithelial characteristics of benign breast to predict risk $[1,9]$, and while sampling is relatively invasive, findings from this study suggest analytic strategies for risk stratification in women who have undergone biopsy following suspicious mammogram findings (false positives).

Acknowledgements We gratefully acknowledge the support of all Normal Breast Study and Mayo Study staff and participants. This work was supported by the Avon Foundation, North Carolina University Cancer Research Fund, National Cancer Institute (R01 CA179715), National Institute of Environmental Health Sciences (U01 ES01947201), and the Intramural Research Program at the National Cancer Institute. LCH was supported in part by the University of North Carolina LCCC Cancer Control and Education Program training grant from the National Cancer Institute (NIH/NCI 5R25CA057726-24).

\section{Compliance with ethical standards}

Conflict of interest The authors declare that they have no conflict of interest.

\section{References}

1. Milanese TR, Hartmann LC, Sellers TA, et al. Age-related lobular involution and risk of breast cancer. J Natl Cancer Inst. 2006;98:1600-7.

2. Ghosh K, Vachon CM, Pankratz VS, et al. Independent association of lobular involution and mammographic breast density with breast cancer risk. J Natl Cancer Inst. 2010;102:1716-23.

3. Figueroa JD, Pfeiffer RM, Brinton LA, et al. Standardized measures of lobular involution and subsequent breast cancer risk among women with benign breast disease: a nested case-control study. Breast Cancer Res Treat. 2016;159:163-72.

4. Baer HJ, Collins LC, Connolly JL, et al. Lobule type and subsequent breast cancer risk: results from the Nurses' Health Studies. Cancer. 2009;115:1404-11.

5. Gierach GL, Patel DA, Pfeiffer RM, et al. Relationship of terminal duct lobular unit involution of the breast with area and volume mammographic densities. Cancer Prev Res. 2016;9:149-58.

6. Russo J, Romero AL, Russo IH. Architectural pattern of the normal and cancerous breast under the influence of parity. Cancer Epidemiol Biomark Prev. 1994;3:219-24.

7. Gertig DM, Stillman IE, Byrne C, et al. Association of age and reproductive factors with benign breast tissue composition. Cancer Epidemiol Biomark Prev. 1999;8:873-9.

8. Sun X, Sandhu R, Figueroa JD, et al. Benign breast tissue composition in breast cancer patients: association with risk factors, clinical variables, and gene expression. Cancer Epidemiol Biomark Prev. 2014;23:2810-8.

9. Figueroa JD, Pfeiffer RM, Patel DA, et al. Terminal duct lobular unit involution of the normal breast: implications for breast cancer etiology. J Natl Cancer Inst. 2014;106:dju286.

10. Li T, Sun L, Miller N, et al. The association of measured breast tissue characteristics with mammographic density and other risk factors for breast cancer. Cancer Epidemiol Biomark Prev. 2005;14:343-9.
11. Henson DE, Tarone RE. Involution and the etiology of breast cancer. Cancer. 1994;74:424-9.

12. Vierkant RA, Hartmann LC, Pankratz VS, et al. Lobular involution: localized phenomenon or field effect? Breast Cancer Res Treat. 2009;117:193-6.

13. Hutson SW, Cowen PN, Bird CC. Morphometric studies of age related changes in normal human breast and their significance for evolution of mammary cancer. J Clin Pathol. 1985;38:281-7.

14. Ghosh K, Brandt KR, Reynolds C, et al. Tissue composition of mammographically dense and non-dense breast tissue. Breast Cancer Res Treat. 2012;131:267-75.

15. Ursin G, Hovanessian-Larsen L, Parisky YR, et al. Greatly increased occurrence of breast cancers in areas of mammographically dense tissue. Breast Cancer Res. 2005;7:R605-608.

16. Sandhu R, Chollet-Hinton L, Kirk EL, et al. Digital histologic analysis reveals morphometric patterns of age-related involution in breast epithelium and stroma. Hum Pathol. 2016;48:60-68.

17. Sickles EA, D'Orsi CJ, Bassett LW, et al. ACR BI-RADS® Mammography. In: ACR BI-RADS® Atlas, Breast Imaging Reporting and Data System. Reston, VA: American College of Radiology; 2013.

18. Casbas-Hernandez P, Sun X, Roman-Perez E, et al. Tumor intrinsic subtype is reflected in cancer-adjacent tissue. Cancer Epidemiol Biomark Prev. 2015;24:406-14.

19. Sun X, Gierach GL, Sandhu R, et al. Relationship of mammographic density and gene expression: analysis of normal breast tissue surrounding breast cancer. Clin Cancer Res. 2013;19:4972-82.

20. Lee J, Koh D, Ong CN. Statistical evaluation of agreement between two methods for measuring a quantitative variable. Comput Biol Med. 1989;19:61-70.

21. Yang XR, Figueroa JD, Falk RT, et al. Analysis of terminal duct lobular unit involution in luminal A and basal breast cancers. Breast Cancer Res. 2012;14:R64.

22. Hawes D, Downey S, Pearce CL, et al. Dense breast stromal tissue shows greatly increased concentration of breast epithelium but no increase in its proliferative activity. Breast Cancer Res. 2006;8: R24.

23. Kim JB, Stein R, O'Hare MJ. Tumour-stromal interactions in breast cancer: the role of stroma in tumourigenesis. Tumour Biol. 2005;26:173-85.

24. Shekhar MP, Pauley R, Heppner G. Host microenvironment in breast cancer development: extracellular matrix-stromal cell contribution to neoplastic phenotype of epithelial cells in the breast. Breast Cancer Res. 2003;5:130-5.

25. Wiseman BS, Werb Z. Stromal effects on mammary gland development and breast cancer. Science. 2002;296:1046-9.

26. Boyd NF, Lockwood GA, Martin LJ, et al. Mammographic density as a marker of susceptibility to breast cancer: a hypothesis. IARC Sci Publ. 2001;154:163-9.

27. Ginsburg OM, Martin LJ, Boyd NF. Mammographic density, lobular involution, and risk of breast cancer. $\mathrm{Br} \mathrm{J}$ Cancer. 2008;99:1369-74.

28. Jindal S, Gao D, Bell P, et al. Postpartum breast involution reveals regression of secretory lobules mediated by tissue-remodeling. Breast Cancer Res. 2014;16:R31.

29. Boyd NF, Melnichouk O, Martin LJ, et al. Mammographic density, response to hormones, and breast cancer risk. J Clin Oncol. 2011;29:2985-92. 